\title{
Optimal Selection Method of Process Patents for Technology Transfer Using Fuzzy Linguistic Computing
}

\author{
Gangfeng Wang, Xitian Tian, and Junhao Geng \\ Institute of CAPP \& Manufacturing Engineering Software, Northwestern Polytechnical University, Xian 710072, China \\ Correspondence should be addressed to Junhao Geng; gengjunhao@nwpu.edu.cn
}

Received 6 January 2014; Accepted 26 February 2014; Published 9 April 2014

Academic Editor: Balaji Raghavan

Copyright ( 2014 Gangfeng Wang et al. This is an open access article distributed under the Creative Commons Attribution License, which permits unrestricted use, distribution, and reproduction in any medium, provided the original work is properly cited.

\begin{abstract}
Under the open innovation paradigm, technology transfer of process patents is one of the most important mechanisms for manufacturing companies to implement process innovation and enhance the competitive edge. To achieve promising technology transfers, we need to evaluate the feasibility of process patents and optimally select the most appropriate patent according to the actual manufacturing situation. Hence, this paper proposes an optimal selection method of process patents using multiple criteria decision-making and 2-tuple fuzzy linguistic computing to avoid information loss during the processes of evaluation integration. An evaluation index system for technology transfer feasibility of process patents is designed initially. Then, fuzzy linguistic computing approach is applied to aggregate the evaluations of criteria weights for each criterion and corresponding subcriteria. Furthermore, performance ratings for subcriteria and fuzzy aggregated ratings of criteria are calculated. Thus, we obtain the overall technology transfer feasibility of patent alternatives. Finally, a case study of aeroengine turbine manufacturing is presented to demonstrate the applicability of the proposed method.
\end{abstract}

\section{Introduction}

Because of fast-changing market trends and customer needs, manufacturing companies should not only emphasize internal research and development of innovative technology $[1,2]$, but also strive to use technology transfer to remedy their technological limitations or to acquire necessary technologies from external sources [3]. Under the open innovation paradigm, technology transfer is one of the most important mechanisms for acquiring knowledge from external sources to secure innovative and advanced technologies in high-tech industries [4-7]. Process patent has become an important knowledge resource for technology transfer due to its innovative and practical features. Many efforts have been made in manufacturing innovation aspects that rely on the knowledge of patents, especially in computer-aided innovation using patents [8-11], such as the promising patents identification using TRIZ (the theory of inventive problem solving) evolution trends [7, 12], patent analysis applying text-mining technique [13], and patent search for technology transfer [14]. However, these technical patents containing innovative principles or methods originally intended to solve certain technical problems or improve the current manufacturing technology. As for the promising technology transfer of patents knowledge into a company, it is necessary to evaluate the technology transfer feasibility of candidate process patents and select the most appropriate alternative in the actual manufacturing environment.

Considering the innovative characteristics of process patents and the manufacturing specificity of enterprise environments, technology transfer feasibility evaluation is needed to examine degree of advanced technology, technology life cycle, and process evolutionary trends, and so forth and to analyze manufacturing profitability for the current process innovation. In order to select process patents for technology transfer, a reasonable evaluation index system is required. Furthermore, quantitative index and qualitative factors based on the evaluation criteria can be evaluated by multiple domain experts or decision-makers. Thus, optimal selection of process patents should be conceptualized as a multiple criteria group decision-making problem $[15,16]$ concerning how to evaluate candidate patents and select the most appropriate alternative. 
Due to the complexity and fuzziness of above problems, it is difficult for decision makers to evaluate the given objects using exact values, but they can express their preference applying fuzzy linguistic evaluation information. Thus, experts devote themselves to judging the technology transfer feasibility by the subjective perception or experiential cognition in the decision-making process. However, there exists a certain extent of fuzziness, uncertainty, and heterogeneity [17]. Besides, it is prone to information loss during the integration processes and because of it the evaluation result of patent performance level may not be consistent with the expectation of experts [18]. There is a need for a rational way to compute the performance ratings of process patents in the process of evaluation integration.

In previous group decision making with linguistic assessment information, two classical computational models were developed to perform linguistic computations based on the fuzzy linguistic approach: linguistic computing model based on membership functions $[19,20]$ and symbolic linguistic computing model [21]. However, both linguistic computing models produce loss of information due to the approximation processes and hence a lack of precision in the results. This loss of information is produced because the information representation model of the fuzzy linguistic approach is discrete in a continuous domain. To avoid information loss and to improve the precision in processes of computing with words, 2-tuple fuzzy linguistic representation model was presented by Herrera and Martínez [18]. In addition, there are several symbolic linguistic computing models widely used in linguistic decision making, which were proposed to improve the accuracy and understandability of the processes of computing with words, such as the virtual linguistic model [22] and the proportional 2-tuple linguistic model [23]. A comparative analysis among the above several models has been carried out by Rodríguez and Martínez [24], and the results showed that the 2-tuple linguistic model keeps the syntax and fuzzy semantics in its results, whereas the other two models do not keep them. And 2-tuple linguistic computational model provides accurate and understandable results because they are represented by means of a linguistic term and a numerical value. For these reasons, it seems to be the most adequate linguistic computing model to deal with linguistic information in decision problems. In recent years, the 2-tuple fuzzy linguistic computing has been used in multiple research fields, for example, the evaluation of new product development performance [25], enterprises' intellectual capital evaluation [26], product design selection [27], and quality evaluation for health-related websites [28], and so forth. The approach not only inherits the existing advantage of fuzzy linguistic computing but also overcomes the disadvantage of information loss of other fuzzy linguistic approaches $[29,30]$.

An optimal selection method based on 2-tuple fuzzy linguistic information is proposed in this research. Firstly, evaluation index system for technology transfer feasibility of process patents is designed by domain experts. And the necessary data from the expert committee can be gathered to determine criteria weights and the performance ratings of candidate process patents. Then, apply 2 -tuple fuzzy linguistic computing approach to aggregate the fuzzy linguistic evaluations of criteria weights for each criterion. Furthermore, the fuzzy linguistic evaluations of performance ratings for subcriteria and the fuzzy aggregated ratings of each criterion can be calculated. And then, we compute the technology transfer feasibility of candidate process patents and select the most appropriate alternative for technology transfer.

The rest of this paper is structured as follows. In Section 2, the demand of optimal selection of process patents is presented, then evaluation index system for technology transfer feasibility of process patents is designed, and some definitions and operations about 2-tuple fuzzy linguistic variable are introduced. In Section 3, in order to implement promising technology transfer, we propose a technology transfer feasibility evaluation model based on fuzzy linguistic information. Then a case study is illustrated in Section 4 for demonstrating the rationality of the proposed approach in practice. Finally, the discussion and conclusions of our work are stated.

\section{Preliminaries}

2.1. The Optimal Selection of Process Patents for Technology Transfer. Patent databases contain mass process patents. Before the technology transfer of process innovation, we can get candidate process patents meeting the basic requirements by retrieving. We call this step the preliminary selection. Then, a feasibility evaluation is needed for candidate process patents in the specific enterprise environment, so as to optimally select the most appropriate process patents and further to achieve process innovation by technology transfer, as shown in Figure 1. Many efforts have been made on patent search for innovation, for example, function-oriented search [31], classification and search by TRIZ principles [13, 32], and concept-based search [33]. In this study, we focus on how to implement optimal selection of patents.

\subsection{Evaluation Index System for Technology Transfer Feasi-} bility of Process Patents. Process patents generally contain innovative manufacturing theories or new process methods within available resources, so as to achieve the desired process objectives, such as processing quality improvement, manufacturing costs reduction, or leading process development. When companies need to implement technology transfer of patents' knowledge into actual process innovation, candidate process patents should be evaluated from process advancement and enterprise future applications of patents technologies. Through the literature review and discussion with domain experts, for example, technology executives, innovators, and so forth, we present a hierarchy evaluation index system for technology transfer feasibility of process patents, as shown in Figure 2. The evaluation index system is composed of three levels: the first level is the overall evaluation objective; the second level is evaluation criteria; and the third level is corresponding subcriteria of each criterion. We divide the technology transfer feasibility into four parts through analyzing manufacturing process innovation: process advancement, enterprise applicability, manufacturing profitability, and competitiveness improvement. 


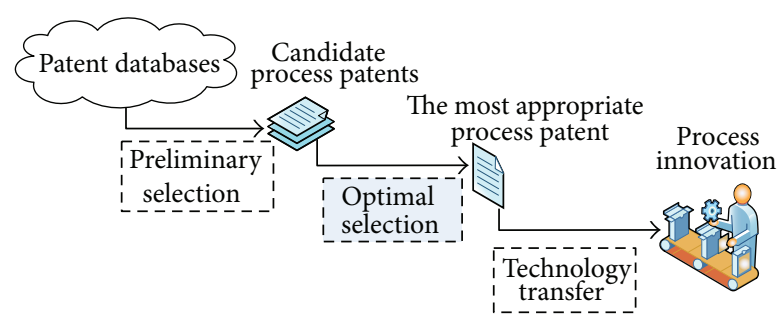

FIGURE 1: The optimal selection of process patents for technology transfer.

These criteria and their relevant subcriteria are illustrated in Figure 2.

2.3. 2-Tuple Fuzzy Linguistic Computing. The fuzzy linguistic approach represents qualitative aspects as linguistic values by means of linguistic variables [34, 35]. The linguistic information with a pair of values is called 2-tuple that is composed of a linguistic term and a number [18]. A 2tuple linguistic variable can be denoted as $\left(s_{i}, \alpha_{i}\right)$, where $s_{i}$ represents the central value of the $i$ th linguistic term, and $\alpha_{i}$ denotes the distance to the central value of the $i$ th linguistic term. For example, a set of terms $S=\left\{s_{0}: \mathrm{VP}, s_{1}\right.$ : $\left.\mathrm{P}, s_{2}: \mathrm{F}, s_{3}: \mathrm{G}, s_{4}: \mathrm{VG}\right\}$ represents that $S$ contains five linguistic terms, "Very poor," "Poor," "Fair," "Good," and "Very good", which are denoted as $s_{0}, s_{1}, s_{2}, s_{3}$, and $s_{4}$, respectively. And each of the linguistic terms is assigned one of five triangle fuzzy numbers which can be represented by a fuzzy membership function [36] (see Figure 3). A 2-tuple linguistic variable set probably comprises three, five, seven, or more terms. Generally, a five-term set has more practical applications [25].

Definition 1. Let $S=\left\{s_{0}, s_{1}, \ldots, s_{g}\right\}$ be a linguistic term set, and $\beta \in[0,1]$ be a crisp value representing the aggregation result of linguistic symbolic translation. Then the symbolic translation process is applied to translate $\beta$ into a 2 -tuple linguistic variable. The generalized translation function $(\Delta)$ can be defined as

$$
\begin{gathered}
\Delta:[0,1] \longrightarrow S \times\left[-\frac{1}{2 g}, \frac{1}{2 g}\right), \\
\Delta(\beta)=\left(s_{i}, \alpha\right)= \begin{cases}s_{i}, & i=\operatorname{round}(\beta \cdot g) \\
\alpha=\beta-\frac{i}{g}, & \alpha \in\left[\frac{-1}{2 g}, \frac{1}{2 g}\right),\end{cases}
\end{gathered}
$$

where round $(\cdot)$ is the usual round operation, $s_{i}$ has the closest index label to $\beta$, and $\alpha$ is the value of the symbolic translation.

Definition 2. On the contrary, a reverse equation $\Delta^{-1}$ is necessary to convert the 2-tuple linguistic variable into its equivalent value $\beta \in[0,1]$, which can be computed by the following formula:

$$
\Delta^{-1}\left(s_{i}, \alpha\right)=\beta=\alpha+\frac{i}{g} .
$$

Definition 3. Let $S=\left\{\left(s_{1}, \alpha_{1}\right), \ldots,\left(s_{n}, \alpha_{n}\right)\right\}$ be a set of 2 tuple fuzzy linguistic variable; their arithmetic mean $\bar{S}$ can be calculated as

$$
\bar{S}=\Delta\left(\frac{1}{n} \sum_{i=1}^{n} \Delta^{-1}\left(s_{i}, \alpha_{i}\right)\right)=\Delta\left(\frac{1}{n} \sum_{i=1}^{n} \beta_{i}\right)=\left(s_{t}, \alpha_{t}\right) .
$$

Definition 4. Let $S=\left\{\left(s_{1}, \alpha_{1}\right), \ldots,\left(s_{n}, \alpha_{n}\right)\right\}$ be a 2-tuple fuzzy linguistic variable set, and let $W=\left\{w_{1}, \ldots, w_{n}\right\}$ be the weight set of linguistic terms; their 2-tuple linguistic weighted average $\bar{S}^{w}$ can be computed as

$$
\begin{aligned}
\bar{S}^{w} & =\Delta\left(\frac{\sum_{i=1}^{n} \Delta^{-1}\left(s_{i}, \alpha_{i}\right) \cdot w_{i}}{\sum_{i=1}^{n} w_{i}}\right) \\
& =\Delta\left(\frac{\sum_{i=1}^{n} \Delta^{-1}\left(\beta_{i} \cdot w_{i}\right)}{\sum_{i=1}^{n} w_{i}}\right)=\left(s^{w}, \alpha^{w}\right),
\end{aligned}
$$

where $s^{w}$ is a linguistic term of set $S$, and $\alpha^{w} \in[-1 / 2 g, 1 / 2 g)$.

In addition, when $W=\left\{\left(w_{1}, \alpha_{w 1}\right), \ldots,\left(w_{n}, \alpha_{w n}\right)\right\}$ is the linguistic weight set of each $s_{i}$, this linguistic weighted average operator can be calculated as

$$
\bar{S}_{l}^{w}=\Delta\left(\frac{\sum_{i=1}^{n}\left[\Delta^{-1}\left(s_{i}, \alpha_{i}\right) \cdot \Delta^{-1}\left(w_{i}, \alpha_{w i}\right)\right]}{\sum_{i=1}^{n} \Delta^{-1}\left(w_{i}, \alpha_{w i}\right)}\right) .
$$

Furthermore, we can compare the linguistic information represented by 2 -tuple fuzzy linguistic variables. If $\left(s_{i}, \alpha_{i}\right)$ and $\left(s_{j}, \alpha_{j}\right)$ are two 2-tuple fuzzy linguistic variables, the comparison of both linguistic variables are shown as follows.

(1) If $i>j$, then $\left(s_{i}, \alpha_{i}\right)$ is better than $\left(s_{j}, \alpha_{j}\right)$;

(2) If $i=j$ and $\alpha_{i}>\alpha_{j}$, then $\left(s_{i}, \alpha_{i}\right)$ is better than $\left(s_{j}, \alpha_{j}\right)$;

(3) If $i=j$ and $\alpha_{i}<\alpha_{j}$, then $\left(s_{i}, \alpha_{i}\right)$ is worse than $\left(s_{j}, \alpha_{j}\right)$;

(4) If $i=j$ and $\alpha_{i}=\alpha_{j}$, then $\left(s_{i}, \alpha_{i}\right)$ is equal to $\left(s_{j}, \alpha_{j}\right)$. 


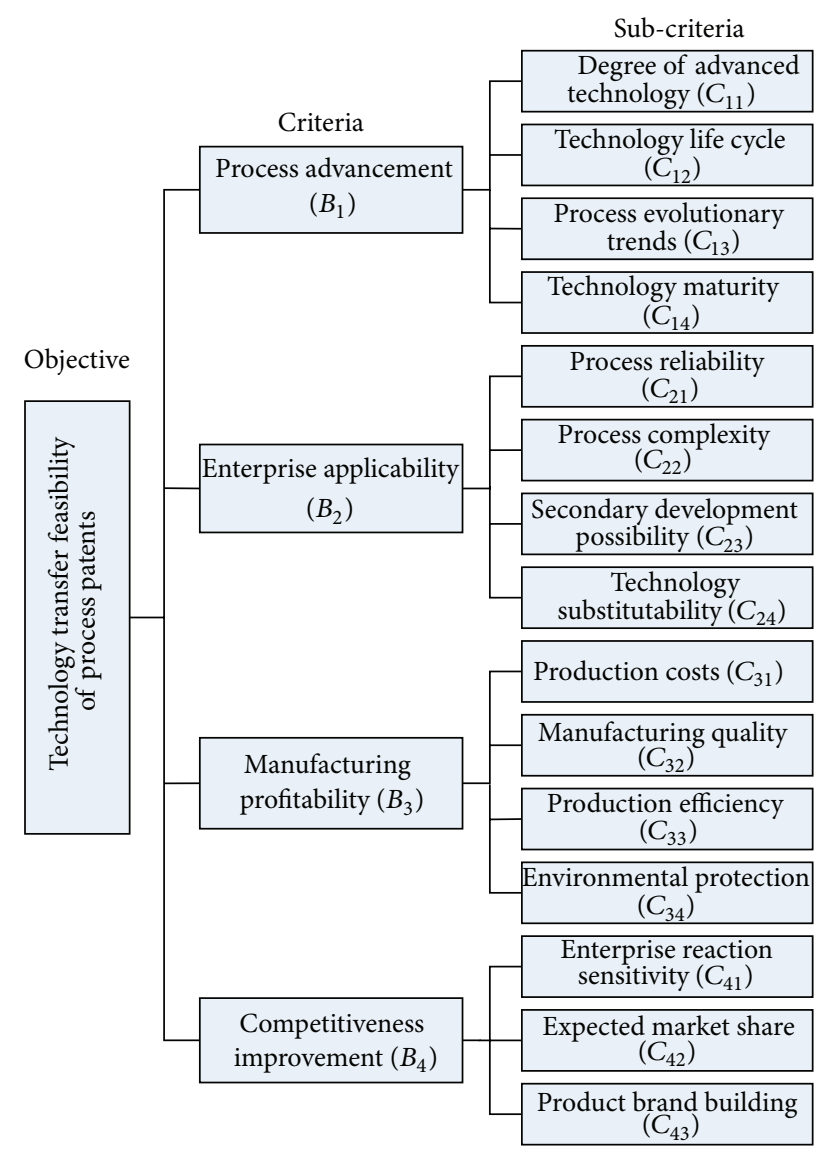

FIGURE 2: The evaluation index system for technology transfer feasibility of process patents.

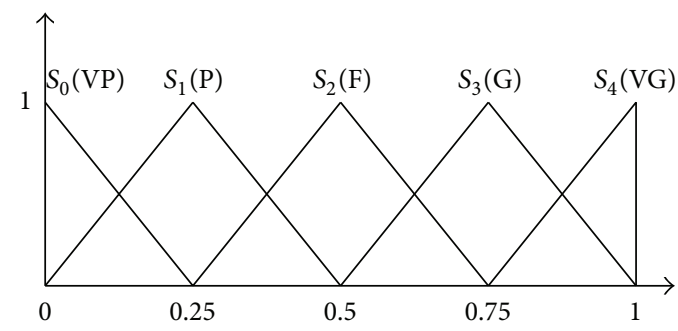

FIGURE 3: Five linguistic terms sets with their semantics.

\section{Technology Transfer Feasibility Evaluation Model of Process Patents}

In manufacturing companies, the promising process patents for process innovation essentially contain new innovative theories and methods. Due to the actual environment of manufacturing companies, it is difficult to evaluate technology transfer feasibility of candidate process patents from multiple criteria using precise values. In this case, the fuzzy linguistic variable is more suitable for domain experts to evaluate the performance of technology transfer feasibility. Hence, a fuzzy linguistic computing method is applied in this paper to measure the technology transfer feasibility level of process patents. The specific procedure of this proposed evaluation model is represented in Figure 4, and the definite process is shown below.

Step 1. Construct a suitable expert committee and design the evaluation index system for technology transfer feasibility of process patents. Let $E=\left\{E_{1}, E_{2}, \ldots, E_{M}\right\}$ be the established expert committee and let $P=\left\{P_{1}, P_{2}, \ldots, P_{K}\right\}$ be a set of candidate process patents. In addition, assume that there are $n$ criteria $B_{i}(i=1,2, \ldots, n)$, and each criterion includes several subcriteria in the evaluation index system for technology transfer feasibility of process patents.

Step 2. Select the linguistic term set $S$ for the criteria weights and the performance ratings and gather necessary data from 


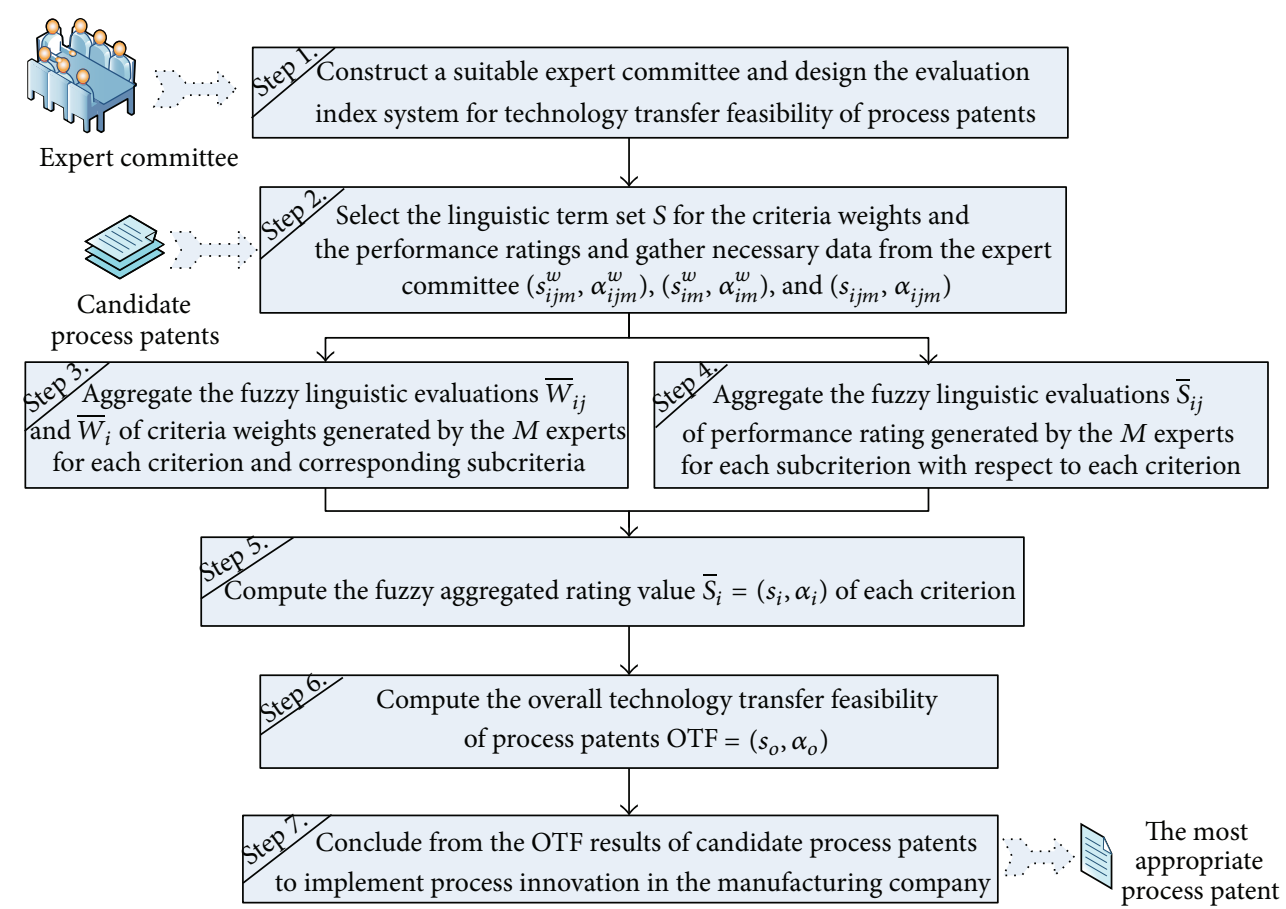

FIGURE 4: Procedure for technology transfer feasibility evaluation of process patents.

the expert committee. Transform these linguistic terms into 2-tuple linguistic variables; for example, $\left(s_{i j m}^{w}, \alpha_{i j m}^{w}\right)$ denote the 2-tuple fuzzy criteria weights of the $j$ th subcriteria with regard to the $i$ th criteria of the $m$ th expert.

Step 3. Aggregate the fuzzy linguistic evaluations of criteria weights generated by the $M$ experts for each criterion and corresponding subcriteria. Here, according to the different requirement of technology transfer for process innovation, the criteria weights of technology transfer feasibility of process patents may vary. The aggregated criteria weighting values of $M$ experts are calculated as follows:

$$
\begin{aligned}
\bar{W}_{i j} & =\Delta\left(\sum_{m=1}^{M}\left[\Delta^{-1}\left(s_{i j m}^{w}, \alpha_{i j m}^{w}\right) \cdot w_{m}^{E}\right]\right) \\
& =\Delta\left(\sum_{m=1}^{M}\left[\beta_{i j m}^{w} \cdot w_{m}^{E}\right]\right)=\left(s_{i j}^{w}, \alpha_{i j}^{w}\right), \\
\bar{W}_{i} & =\Delta\left(\sum_{m=1}^{M}\left[\Delta^{-1}\left(s_{i m}^{w}, \alpha_{i m}^{w}\right) \cdot w_{m}^{E}\right]\right) \\
& =\Delta\left(\sum_{m=1}^{M}\left[\beta_{i m}^{w} \cdot w_{m}^{E}\right]\right)=\left(s_{i}^{w}, \alpha_{i}^{w}\right),
\end{aligned}
$$

where $s_{i j m}^{w}$ is the fuzzy importance of subcriteria $j$ with respect to $B_{i}$ of the $m$ th expert, $s_{i m}^{w}$ is the fuzzy importance of $B_{i}$ of the $m$ th expert, and $w_{m}^{E} \in[0,1]$ is the expert weight of the $m$ th expert in determination of criteria importance, $\sum_{m=1}^{M} w_{m}^{E}=1$.
Particularly, when the expert weights are equal to each other, the aggregated criteria weighting values can be obtained using (3):

$$
\begin{aligned}
\bar{W}_{i j} & =\Delta\left(\frac{1}{M} \sum_{m=1}^{M} \Delta^{-1}\left(s_{i j m}^{w}, \alpha_{i j m}^{w}\right)\right) \\
& =\Delta\left(\frac{1}{M} \sum_{m=1}^{M} \beta_{i j m}^{w}\right)=\left(s_{i j}^{w}, \alpha_{i j}^{w}\right), \\
\bar{W}_{i} & =\Delta\left(\frac{1}{M} \sum_{m=1}^{M} \Delta^{-1}\left(s_{i m}^{w}, \alpha_{i m}^{w}\right)\right) \\
& =\Delta\left(\frac{1}{M} \sum_{m=1}^{M} \beta_{i m}^{w}\right)=\left(s_{i}^{w}, \alpha_{i}^{w}\right) .
\end{aligned}
$$

Step 4. Aggregate the fuzzy linguistic evaluations of performance rating generated by the $M$ experts for each subcriterion with respect to each criterion. Assume that expert weights are the same in performance evaluation of process patents, and applying (3) to obtain the aggregation of fuzzy linguistic evaluation values, we have

$$
\begin{aligned}
\bar{S}_{i j} & =\Delta\left(\frac{1}{M} \sum_{m=1}^{M} \Delta^{-1}\left(s_{i j m}, \alpha_{i j m}\right)\right) \\
& =\Delta\left(\frac{1}{M} \sum_{m=1}^{M} \beta_{i j m}\right)=\left(s_{i j}, \alpha_{i j}\right),
\end{aligned}
$$

where $s_{i j m}$ is the fuzzy rating of subcriteria $j$ with respect to $B_{i}$ of the $m$ th expert. 
Step 5. Compute the fuzzy aggregated ratings of each criterion by (4):

$$
\begin{aligned}
\bar{S}_{i} & =\Delta\left(\frac{\sum_{j=1}^{n_{i}}\left[\Delta^{-1}\left(r_{i j}, \alpha_{i j}\right) \cdot \beta_{i j}^{w}\right]}{\sum_{j=1}^{n_{i}} \beta_{i j}^{w}}\right) \\
& =\Delta\left(\frac{\sum_{j=1}^{n_{i}}\left[\left(\beta_{i j} \cdot \beta_{i j}^{w}\right)\right]}{\sum_{j=1}^{n_{i}} \beta_{i j}^{w}}\right)=\left(s_{i}, \alpha_{i}\right),
\end{aligned}
$$

where $\beta_{i j}=\Delta^{-1}\left(r_{i j}, \alpha_{i j}\right), \beta_{i j}^{w}=\Delta^{-1}\left(w_{i j}, \alpha_{i j}^{w}\right), s_{i}$ is on the subcriteria of the set $S$, and $\alpha_{i} \in[-1 / 2 g, 1 / 2 g)$ for $i=$ $1,2, \ldots, n$.

Step 6. Compute the overall technology transfer feasibility (OTF) of process patents, and the linguistic term $s_{o}$ can be used to represent the feasibility level of process patents for process innovation in the manufacturing company:

$$
\begin{aligned}
\mathrm{OTF} & =\Delta\left(\frac{\sum_{i=1}^{n}\left(\Delta^{-1}\left(r_{i}, \alpha_{i}\right) \cdot \beta_{i}^{w}\right)}{\sum_{i=1}^{n} \beta_{i}^{w}}\right) \\
& =\Delta\left(\frac{\sum_{i=1}^{n}\left(\beta_{i} \cdot \beta_{i}^{w}\right)}{\sum_{i=1}^{n} \beta_{i}^{w}}\right)=\left(s_{o}, \alpha_{o}\right),
\end{aligned}
$$

where $\beta_{i}=\Delta^{-1}\left(r_{i}, \alpha_{i}\right), \beta_{i}^{w}=\Delta^{-1}\left(w_{i}, \alpha_{w_{i}}\right), s_{o}$ is on the subcriteria of the set $S$, and $\alpha_{o} \in[-1 / 2 g, 1 / 2 g)$.

Step 7. Conclude from the OTF results of candidate process patents to implement process innovation in the manufacturing company.

\section{Case Study}

In this case, the proposed method is applied to optimally select the most appropriate alternative for technology transfer of turbine manufacturing in an aero-engine company. Through the preliminary selection, there are six patent alternatives needing to be evaluated (as shown in Table 1): $\left\{P_{1}, P_{2}, P_{3}, P_{4}, P_{5}, P_{6}\right\}$. To gather necessary data, the researchers conduct in-depth interview with the expert committee including process researcher, TRIZ expert, and technical manager and explain the linguistic variable and its semantics to them. According to the proposed method, the process of most appropriate patent selection is presented as follows.

Step 1. A expert committee has three experts: $\left\{E_{1}, E_{2}, E_{3}\right\}$. The evaluation criteria and subcriteria are illustrated in Figure 2.

Step 2. Each expert uses the linguistic importance variables to describe the importance of criteria and subcriteria and use the linguistic rating variables to evaluate performance ratings of subcriteria for the six alternatives. The linguistic variables of the importance and rating are displayed in Table 2. The necessary data of criteria weights and performance ratings are given in Tables 3 and 4, respectively.

Step 3. During the evaluation performance ratings of process patents, criteria weights can be considered to be equal under normal circumstances. In the criteria weights determination of this case study, we suppose the vector of expert weight is $[0.4,0.3,0.3]$ according to the professional knowledge and experience of experts and company-specific circumstances. Thus, by using (6), the aggregated criteria weights of each criterion and corresponding subcriteria are obtained, as shown in Table 3. For example, the weights of "Degree of advanced technology" and "Process advancement" are calculated as

$$
\begin{aligned}
\bar{W}_{11}=\Delta\left(\sum\left[\Delta^{-1}\left(s_{4}, 0\right) \cdot 0.4\right],\left[\Delta^{-1}\left(s_{3}, 0\right) \cdot 0.3\right],\right. \\
{\left.\left[\Delta^{-1}\left(s_{4}, 0\right) \cdot 0.3\right]\right) } \\
=\Delta(0.925)=\left(s_{4},-0.075\right), \\
\bar{W}_{1}=\Delta\left(\sum\left[\Delta^{-1}\left(s_{3}, 0\right) \cdot 0.4\right],\left[\Delta^{-1}\left(s_{4}, 0\right) \cdot 0.3\right],\right. \\
\left.\quad\left[\Delta^{-1}\left(s_{4}, 0\right) \cdot 0.3\right]\right) \\
=\Delta(0.9)=\left(s_{4},-0.1\right) .
\end{aligned}
$$

Step 4. We assume expert weights are equal in performance evaluation and use (8) to compute the aggregation of fuzzy linguistic evaluation values of subcriteria. For example, the evaluation values of "Degree of advanced technology" for $P_{1}$ is calculated as

$$
\begin{aligned}
\bar{S}_{11} & =\Delta\left(\frac{1}{3} \sum \Delta^{-1}\left(s_{3}, 0\right), \Delta^{-1}\left(s_{4}, 0\right), \Delta^{-1}\left(s_{4}, 0\right)\right) \\
& =\Delta(0.917)=\left(s_{4},-0.083\right) .
\end{aligned}
$$

Step 5. The fuzzy aggregated ratings of each criterion of $P_{1}$ are shown in Table 5. For example, fuzzy rating value of "Process advancement" for $P_{1}$ is obtained by (9) as

$$
\begin{aligned}
& \bar{S}_{1}=\Delta(\left(\sum \Delta^{-1}\left(s_{4},-0.083\right) \cdot \Delta^{-1}\left(s_{4},-0.075\right),\right. \\
& \Delta^{-1}\left(s_{3},-0.083\right) \cdot \Delta^{-1}\left(s_{3}, 0\right), \Delta^{-1}\left(s_{3}, 0\right) \\
& \cdot \Delta^{-1}\left(s_{3}, 0.075\right), \Delta^{-1}\left(s_{3},-0.083\right) \\
&\left.\cdot \Delta^{-1}\left(s_{3},-0.025\right)\right) \times\left(\sum \Delta^{-1}\left(s_{4},-0.075\right),\right. \Delta^{-1}\left(s_{3}, 0\right), \Delta^{-1}\left(s_{3}, 0.075\right), \\
&\left.\left.\Delta^{-1}\left(s_{3},-0.025\right)\right)^{-1}\right)
\end{aligned}
$$$$
=\Delta(0.76)=\left(s_{3}, 0.01\right) \text {. }
$$ 
TABLE 1: Candidate process patents for technology transfer of turbine manufacturing.

\begin{tabular}{|c|c|c|}
\hline & Patent number & Title \\
\hline$P_{1}$ & US20130199041 & Method for manufacturing microgas turbine \\
\hline$P_{2}$ & US20130199043 & $\begin{array}{l}\text { Method of manufacturing a turbine blade, system for manufacturing a turbine blade, } \\
\text { intermediate member for manufacturing a turbine blade, and turbine blade manufactured by } \\
\text { means of the aforementioned method }\end{array}$ \\
\hline$P_{3}$ & CN100529138 & $\begin{array}{l}\text { Pipe for steam turbine, manufacturing process of same, and steam turbine power plant using } \\
\text { those pipes }\end{array}$ \\
\hline$P_{4}$ & WO2013060977 & $\begin{array}{l}\text { Method for manufacturing a turbine nozzle guide vanes sector or a compressor guide vanes } \\
\text { sector from composite material for a turbomachine }\end{array}$ \\
\hline$P_{5}$ & US8499449 B2 & Method for manufacturing a turbine blade \\
\hline$P_{6}$ & CA2714809 C & System for washing an aerogas turbine engine \\
\hline
\end{tabular}

TABLE 2: Linguistic variables of the importance and rating.

\begin{tabular}{|c|c|c|c|}
\hline \multirow{2}{*}{ Linguistic label } & \multicolumn{2}{|c|}{ Linguistic term } & \multirow{2}{*}{ Triangular fuzzy number } \\
\hline & Importance & Rating & \\
\hline$s_{0}$ & Very unimportant (VU) & Very poor (VP) & $(0,0,0.25)$ \\
\hline$s_{1}$ & Unimportant (U) & Poor $(\mathrm{P})$ & $(0,0.25,0.5)$ \\
\hline$s_{2}$ & Fair $(\mathrm{F})$ & Fair $(\mathrm{F})$ & $(0.25,0.5,0.75)$ \\
\hline$s_{3}$ & Important (I) & Good (G) & $(0.5,0.75,1.0)$ \\
\hline$s_{4}$ & Very important (VI) & Very good (VG) & $(0.75,1.0,1.0)$ \\
\hline
\end{tabular}

Step 6. By using (10), we can compute the OTF of six alternatives, as shown in Table 6. For example, the OTF of $P_{1}$ is calculated as

$$
\begin{aligned}
\operatorname{OTF}\left(P_{1}\right)=\Delta( & \left(\sum \Delta^{-1}\left(s_{3}, 0.01\right) \cdot \Delta^{-1}\left(s_{4},-0.1\right),\right. \\
& \Delta^{-1}\left(s_{3}, 0.03\right) \cdot \Delta^{-1}\left(s_{3}, 0.075\right), \\
& \Delta^{-1}\left(s_{3}, 0.06\right) \cdot \Delta^{-1}\left(s_{3}, 0.1\right), \Delta^{-1}\left(s_{3}, 0.03\right) \\
& \left.\cdot \Delta^{-1}\left(s_{3},-0.1\right)\right) \\
& \times\left(\sum \Delta^{-1}\left(s_{4},-0.1\right), \Delta^{-1}\left(s_{3}, 0.075\right),\right. \\
= & \left.\left.\Delta^{-1}\left(s_{3}, 0.1\right), \Delta^{-1}\left(s_{3},-0.1\right)\right)^{-1}\right) \\
= & (0.782)=\left(s_{3}, 0.032\right) .
\end{aligned}
$$

Step 7. As shown in Table 6, the ranking of candidate patents is obtained from the overall evaluation results. Thus, the OTF of alternative $P_{1},\left(s_{3}, 0.032\right)$, represents its feasibility is slightly higher than "Good", and the alternative $P_{1}$ is worse than the alternative $P_{2}$ since $P_{2}$ is farther from linguistic term $s_{3}$ and closer to linguistic term $s_{4}$. The overall ranking of the six patents is $P_{2}>P_{6}>P_{1}>P_{4}>P_{3}>P_{5}$, where the symbol " $>$ " denotes superior to. Hence, $P_{2}$ is the most appropriate patent, and $P_{6}$ is followed. In addition, the actual results of process innovation in the aeroengine company show that the technology transfer of turbine manufacturing has been successfully achieved by introducing the patent $P_{2}$. We can see that the overall evaluation results and ranking of candidate patents are consistent with description of expert committee, and the proposed method is applicable for optimal selection of process patents.

\section{Discussion and Conclusions}

Because of the complexity and fuzziness of technology transfer feasibility evaluation, experts often evaluate the importance and the ratings of qualitative criteria in the form of linguistic variable. In this research, we propose an optimal selection method of process patents using 2tuple fuzzy linguistic computing and implement a case study of aeroengine turbine manufacturing by the method. The results show that the proposed method can obtain the overall evaluation results, which contain central value $s_{i}$ and the distance to the value $\alpha_{i}$. This facilitates optimal selection and is suitable to avoid information loss during the processes of evaluation integration. And from the current application point of view, the proposed method is effective and applicable for process innovation. The proposed method can support technology transfer of process patents under the open innovation paradigm, and the evaluation results can provide a reference for manufacturing companies to implement process innovation and enhance the competitive edge.

The requirements of process innovation vary during different stages of the production. Thus, evaluation criteria weights of technology transfer feasibility may be different for various stages of process innovation, even within the same company. Hence, criteria weights are aggregated initially by 
TABLE 3: Linguistic evaluation and weighting value of importance of each criterion and corresponding sub-criteria.

\begin{tabular}{|c|c|c|c|c|c|}
\hline \multirow{2}{*}{ Criteria } & \multirow{2}{*}{ Subcriteria } & \multicolumn{3}{|c|}{ Importance } & \multirow{2}{*}{ Aggregated weighting value } \\
\hline & & $E_{1}$ & $E_{2}$ & $E_{3}$ & \\
\hline \multirow{5}{*}{ Process advancement $\left(B_{1}\right)$} & & I & VI & VI & $\left(s_{4},-0.1\right)$ \\
\hline & Degree of advanced technology $\left(C_{11}\right)$ & VI & I & $\mathrm{VI}$ & $\left(s_{4},-0.075\right)$ \\
\hline & Technology life cycle $\left(C_{12}\right)$ & $\mathrm{I}$ & VI & $\mathrm{F}$ & $\left(s_{3}, 0\right)$ \\
\hline & Process evolutionary trends $\left(C_{13}\right)$ & I & I & VI & $\left(s_{3}, 0.075\right)$ \\
\hline & Technology maturity $\left(C_{14}\right)$ & $\mathrm{F}$ & VI & $\mathrm{I}$ & $\left(s_{3},-0.025\right)$ \\
\hline \multirow{5}{*}{ Enterprise applicability $\left(B_{2}\right)$} & & I & VI & I & $\left(s_{3}, 0.075\right)$ \\
\hline & Process reliability $\left(C_{21}\right)$ & I & VI & VI & $\left(s_{4},-0.1\right)$ \\
\hline & Process complexity $\left(C_{22}\right)$ & $\mathrm{F}$ & I & I & $\left(s_{3},-0.1\right)$ \\
\hline & Secondary development possibility $\left(C_{23}\right)$ & I & $\mathrm{F}$ & I & $\left(s_{3},-0.075\right)$ \\
\hline & Technology substitutability $\left(C_{24}\right)$ & I & VI & $\mathrm{F}$ & $\left(s_{3}, 0\right)$ \\
\hline \multirow{5}{*}{ Manufacturing profitability $\left(B_{3}\right)$} & & VI & $\mathrm{I}$ & I & $\left(s_{3}, 0.1\right)$ \\
\hline & Production costs $\left(C_{31}\right)$ & $\mathrm{I}$ & VI & I & $\left(s_{3}, 0.075\right)$ \\
\hline & Manufacturing quality $\left(C_{32}\right)$ & VI & VI & I & $\left(s_{4},-0.075\right)$ \\
\hline & Production efficiency $\left(C_{33}\right)$ & I & I & VI & $\left(s_{3}, 0.075\right)$ \\
\hline & Environmental protection $\left(C_{34}\right)$ & $\mathrm{I}$ & VI & $\mathrm{F}$ & $\left(s_{3}, 0\right)$ \\
\hline \multirow{4}{*}{ Competitiveness improvement $\left(B_{4}\right)$} & & $\mathrm{F}$ & I & I & $\left(s_{3},-0.1\right)$ \\
\hline & Enterprise reaction sensitivity $\left(C_{41}\right)$ & VI & I & VI & $\left(s_{4},-0.075\right)$ \\
\hline & Expected market share $\left(C_{42}\right)$ & I & I & VI & $\left(s_{3}, 0.075\right)$ \\
\hline & Product brand building $\left(C_{43}\right)$ & $\mathrm{I}$ & $\mathrm{F}$ & I & $\left(s_{3},-0.075\right)$ \\
\hline
\end{tabular}

TABLE 4: The performance ratings of candidate process patents.

\begin{tabular}{|c|c|c|c|c|c|c|c|c|c|c|c|c|c|c|c|c|}
\hline & \multicolumn{15}{|c|}{ Ratings for subcriteria } \\
\hline & & $C_{11}$ & $C_{12}$ & $C_{13}$ & $C_{14}$ & $C_{21}$ & $C_{22}$ & $C_{23}$ & $C_{24}$ & $C_{31}$ & $C_{32}$ & $C_{33}$ & $C_{34}$ & $C_{41}$ & $C_{42}$ & $C_{43}$ \\
\hline & $P_{1}-D_{1}$ & G & $\mathrm{F}$ & G & $\mathrm{F}$ & VG & G & $\mathrm{F}$ & $\mathrm{G}$ & $\mathrm{F}$ & G & $\mathrm{G}$ & VG & $G$ & $\mathrm{~F}$ & G \\
\hline \multirow[t]{3}{*}{$P_{1}$} & $P_{1}-D_{2}$ & VG & G & G & G & G & VG & $\mathrm{F}$ & $\mathrm{F}$ & G & VG & G & VG & VG & G & G \\
\hline & $P_{1}-D_{3}$ & VG & G & G & G & G & VG & G & G & G & VG & G & G & G & G & VG \\
\hline & $P_{2}-D_{1}$ & VG & G & VG & G & G & VG & VG & VG & G & VG & G & VG & VG & VG & G \\
\hline \multirow[t]{3}{*}{$P_{2}$} & $P_{2}-D_{2}$ & VG & G & G & VG & $\mathrm{F}$ & VG & VG & G & VG & G & G & VG & VG & $\mathrm{G}$ & VG \\
\hline & $P_{2}-D_{3}$ & G & G & VG & VG & G & $\mathrm{F}$ & G & $\mathrm{G}$ & G & VG & VG & VG & VG & G & VG \\
\hline & $P_{3}-D_{1}$ & $\mathrm{~F}$ & G & G & $\mathrm{F}$ & $\mathrm{G}$ & G & $\mathrm{F}$ & VG & F & VP & $\mathrm{F}$ & $\mathrm{G}$ & $\mathrm{G}$ & $\mathrm{F}$ & $\mathrm{G}$ \\
\hline \multirow[t]{3}{*}{$P_{3}$} & $P_{3}-D_{2}$ & G & G & $\mathrm{F}$ & $\mathrm{P}$ & G & $\mathrm{G}$ & $\mathrm{F}$ & $\mathrm{G}$ & F & $\mathrm{P}$ & $\mathrm{F}$ & $\mathrm{G}$ & VG & $\mathrm{F}$ & $\mathrm{F}$ \\
\hline & $P_{3}-D_{3}$ & $\mathrm{~F}$ & $\mathrm{~F}$ & VG & G & $\mathrm{F}$ & $\mathrm{F}$ & $\mathrm{G}$ & G & F & $\mathrm{P}$ & $\mathrm{P}$ & VG & $\mathrm{G}$ & $\mathrm{F}$ & $\mathrm{G}$ \\
\hline & $P_{4}-D_{1}$ & $\mathrm{G}$ & $\mathrm{G}$ & $\mathrm{G}$ & $\mathrm{F}$ & G & $\mathrm{G}$ & VG & $\mathrm{G}$ & VG & $\mathrm{F}$ & $\mathrm{G}$ & $\mathrm{F}$ & $\mathrm{F}$ & G & $\mathrm{G}$ \\
\hline \multirow[t]{3}{*}{$P_{4}$} & $P_{4}-D_{2}$ & G & VG & $\mathrm{F}$ & G & $\mathrm{F}$ & $\mathrm{G}$ & $\mathrm{G}$ & $\mathrm{F}$ & $\mathrm{G}$ & G & $\mathrm{F}$ & G & $\mathrm{G}$ & $\mathrm{F}$ & $\mathrm{G}$ \\
\hline & $P_{4}-D_{3}$ & G & G & VG & G & VG & G & G & G & G & G & $\mathrm{F}$ & $\mathrm{F}$ & G & $\mathrm{F}$ & G \\
\hline & $P_{5}-D_{1}$ & $\mathrm{~F}$ & $\mathrm{~F}$ & G & $\mathrm{F}$ & G & $\mathrm{P}$ & $\mathrm{P}$ & $\mathrm{F}$ & VG & G & G & G & G & G & $\mathrm{F}$ \\
\hline \multirow[t]{3}{*}{$P_{5}$} & $P_{5}-D_{2}$ & $\mathrm{P}$ & $\mathrm{F}$ & $\mathrm{F}$ & $\mathrm{F}$ & G & $\mathrm{F}$ & $\mathrm{P}$ & $\mathrm{P}$ & $\mathrm{G}$ & $\mathrm{F}$ & $\mathrm{G}$ & $\mathrm{F}$ & $\mathrm{F}$ & $\mathrm{G}$ & $\mathrm{F}$ \\
\hline & $P_{5}-D_{3}$ & $\mathrm{~F}$ & $\mathrm{G}$ & $\mathrm{P}$ & $\mathrm{F}$ & $\mathrm{P}$ & $\mathrm{P}$ & $\mathrm{P}$ & $\mathrm{P}$ & G & $\mathrm{F}$ & $\mathrm{G}$ & $\mathrm{G}$ & $\mathrm{G}$ & $\mathrm{F}$ & G \\
\hline & $P_{6}-D_{1}$ & VG & VG & VG & $\mathrm{G}$ & $\mathrm{G}$ & $\mathrm{G}$ & $\mathrm{F}$ & $\mathrm{G}$ & VG & $\mathrm{G}$ & $\mathrm{G}$ & VG & VG & VG & VG \\
\hline \multirow{2}{*}{$P_{6}$} & $P_{6}-D_{2}$ & $\mathrm{G}$ & VG & VG & VG & G & VG & G & $\mathrm{G}$ & VG & G & $\mathrm{G}$ & $\mathrm{G}$ & VG & $\mathrm{G}$ & VG \\
\hline & $P_{6}-D_{3}$ & VG & $\mathrm{G}$ & $\mathrm{G}$ & VG & VG & VG & G & G & G & VG & $\mathrm{G}$ & G & $\mathrm{G}$ & VG & VG \\
\hline
\end{tabular}

experts having unequal expert weights, and then performance evaluation is calculated. On this point, our method is designed by considering the variability of innovation. Because of this, the results obtained in this case study are specific for technology transfer of process innovation in that company; the results may be different for other companies. In addition, the evaluation results do not indicate the quality or level of patents themselves, but they just show the ranking of candidate process patents for technology transfer of a particular process innovation in the company.

To facilitate description of the proposed method and to simplify the calculations, the expert committee chooses only three experts based on the company-specific circumstances in the case study of this paper. In practical decisions, we can 
TABLE 5: The aggregated results and overall technology transfer feasibility of $P_{1}$.

\begin{tabular}{|c|c|c|c|c|c|c|}
\hline \multirow{2}{*}{ Criteria and subcriteria } & \multicolumn{3}{|c|}{ Rating $\left(P_{1}\right)$} & \multirow{2}{*}{ Fuzzy evaluation $\left(P_{1}\right)$} & \multirow{2}{*}{ Weighted rating $\left(P_{1}\right)$} & \multirow{2}{*}{$\operatorname{OTF}\left(P_{1}\right)$} \\
\hline & $D_{1}$ & $D_{2}$ & $D_{3}$ & & & \\
\hline \multicolumn{7}{|l|}{ Process advancement $\left(B_{1}\right)$} \\
\hline Degree of advanced technology $\left(C_{11}\right)$ & G & VG & VG & $\left(s_{4},-0.083\right)$ & \multirow{4}{*}{$\left(s_{3}, 0.01\right)$} & \\
\hline Technology life cycle $\left(C_{12}\right)$ & $\mathrm{F}$ & G & G & $\left(s_{3},-0.083\right)$ & & \\
\hline Process evolutionary trends $\left(C_{13}\right)$ & G & G & G & $\left(s_{3}, 0\right)$ & & \\
\hline Technology maturity $\left(C_{14}\right)$ & $\mathrm{F}$ & G & G & $\left(s_{3},-0.083\right)$ & & \\
\hline \multicolumn{7}{|l|}{ Enterprise applicability $\left(B_{2}\right)$} \\
\hline Process reliability $\left(C_{21}\right)$ & VG & G & G & $\left(s_{3}, 0.083\right)$ & \multirow{4}{*}{$\left(s_{3}, 0.03\right)$} & \\
\hline Process complexity $\left(C_{22}\right)$ & G & VG & VG & $\left(s_{4},-0.083\right)$ & & \\
\hline Secondary development possibility $\left(C_{23}\right)$ & $\mathrm{F}$ & $\mathrm{F}$ & G & $\left(s_{2}, 0.083\right)$ & & \\
\hline Technology substitutability $\left(C_{24}\right)$ & G & $\mathrm{F}$ & G & $\left(s_{3},-0.083\right)$ & & $\left(s_{3}, 0.032\right)$ \\
\hline \multicolumn{7}{|l|}{ Manufacturing profitability $\left(B_{3}\right)$} \\
\hline Production costs $\left(C_{31}\right)$ & $\mathrm{F}$ & G & G & $\left(s_{3},-0.083\right)$ & \multirow{4}{*}{$\left(s_{3}, 0.06\right)$} & \\
\hline Manufacturing quality $\left(C_{32}\right)$ & G & VG & VG & $\left(s_{4},-0.083\right)$ & & \\
\hline Production efficiency $\left(C_{33}\right)$ & G & G & G & $\left(s_{3}, 0\right)$ & & \\
\hline Environmental protection $\left(C_{34}\right)$ & VG & VG & G & $\left(s_{4},-0.083\right)$ & & \\
\hline \multicolumn{7}{|l|}{ Competitiveness improvement $\left(B_{4}\right)$} \\
\hline Enterprise reaction sensitivity $\left(C_{41}\right)$ & G & VG & G & $\left(s_{3}, 0.083\right)$ & \multirow{3}{*}{$\left(s_{3}, 0.03\right)$} & \\
\hline Expected market share $\left(C_{42}\right)$ & $\mathrm{F}$ & G & G & $\left(s_{3},-0.083\right)$ & & \\
\hline Product brand building $\left(C_{43}\right)$ & G & $\mathrm{G}$ & VG & $\left(s_{3}, 0.083\right)$ & & \\
\hline
\end{tabular}

TABLE 6: The overall evaluation results and ranking of candidate patents.

\begin{tabular}{lcccccc}
\hline & $P_{1}$ & $P_{2}$ & $P_{3}$ & $P_{4}$ & $P_{5}$ \\
\hline OTF & $\left(s_{3}, 0.032\right)$ & $\left(s_{3}, 0.121\right)$ & $\left(s_{2}, 0.110\right)$ & $\left(s_{3},-0.039\right)$ & $\left(s_{2}, 0.053\right)$ & $\left(s_{3}, 0.118\right)$ \\
ranking & 3 & 1 & 5 & 4 & 6 & 2 \\
\hline
\end{tabular}

increase the number of experts to avoid the arbitrariness. Additionally the method and results of this study can also be applied in the evaluation and selection of other innovative candidates, such as process innovation solutions. However, we consider only the subjective evaluation of technology transfer feasibility in this paper; actually the objective evaluation is also important for optimal selection of process patents in practice. In the future, we will explore objective evaluation from the perspectives of patent innovation principle and corresponding enterprise manufacturing data by artificial intelligence, for example, data mining techniques; thus, process patents for technology transfer will be jointly considered objectively and subjectively.

\section{Conflict of Interests}

The authors declare that there is no conflict of interests regarding the publishing of this paper.

\section{Acknowledgments}

This work is supported by the National Natural Science Foundation of China under Grant no. 51105313.

\section{References}

[1] B. Cassiman and R. Veugelers, "In search of complementarity in innovation strategy: internal $\mathrm{R} \& \mathrm{D}$ and external knowledge acquisition," Management Science, vol. 52, no. 1, pp. 68-82, 2006.

[2] M. Elmquist and P. le Masson, "The value of a "failed" R\&D project: an emerging evaluation framework for building innovative capabilities," $R$ and D Management, vol. 39, no. 2, pp. 136$152,2009$.

[3] H. Park, J. Yoon, and K. Kim, "Using function-based patent analysis to identify potential application areas of technology for technology transfer," Expert Systems with Applications, vol. 40, no. 13, pp. 5260-5265, 2013.

[4] H. W. Chesbrough, “The era of open innovation," MIT Sloan Management Review, vol. 44, no. 3, pp. 35-41, 2003.

[5] F. Carbone, J. Contreras, J. Z. Hernández, and J. M. GomezPerez, "Open Innovation in an Enterprise 3.0 framework: three case studies," Expert Systems with Applications, vol. 39, no. 10, pp. 8929-8939, 2012.

[6] E. K. R. E. Huizingh, "Open innovation: state of the art and future perspectives," Technovation, vol. 31, no. 1, pp. 2-9, 2011.

[7] H. Park, J. J. Ree, and K. Kim, "Identification of promising patents for technology transfers using TRIZ evolution trends," Expert Systems with Applications, vol. 40, no. 2, pp. 736-743, 2013.

[8] U. Cugini, G. Cascini, M. Muzzupappa, and V. Nigrelli, "Integrated Computer-Aided innovation: the PROSIT approach," Computers in Industry, vol. 60, no. 8, pp. 629-641, 2009. 
[9] S. Hüsig and S. Kohn, "Computer aided innovation-State of the art from a new product development perspective," Computers in Industry, vol. 60, no. 8, pp. 551-562, 2009.

[10] G. Wang, X. Tian, J. Geng, and B. Guo, "A process innovation knowledge management framework and its application," Advanced Materials Research, vol. 655-657, pp. 2299-2306, 2013.

[11] C. Zanni-Merk, D. Cavallucci, and F. Rousselot, "An ontological basis for computer aided innovation," Computers in Industry, vol. 60, no. 8, pp. 563-574, 2009.

[12] I. M. Ilevbare, D. Probert, and R. Phaal, "A review of TRIZ, and its benefits and challenges in practice," Technovation, vol. 33, no. 2-3, pp. 30-37, 2013.

[13] G. Cascini and D. Russo, "Computer-aided analysis of patents and search for TRIZ contradictions," International Journal of Product Development, vol. 4, no. 1-2, pp. 52-67, 2007.

[14] D. Russo, T. Montecchi, and L. Ying, "Functional-based search for patent technology transfer," in Proceedings of the ASME International Design Engineering Technical Conferences and Computers and Information in Engineering Conference (IDETC/CIE '12), pp. 529-539, American Society of Mechanical Engineers, Chicago, Ill, USA, August 2012.

[15] M. Li, "Extension of axiomatic design method for fuzzy linguistic multiple criteria group decision making with incomplete weight information," Mathematical Problems in Engineering, vol. 2012, Article ID 634326, 17 pages, 2012.

[16] C. M. Wu, C. L. Hsieh, and K. L. Chang, "A hybrid multiple criteria decision making model for supplier selection," Mathematical Problems in Engineering, vol. 2013, Article ID 324283, 8 pages, 2013.

[17] S. J. J. Chen, C. L. Hwang, M. J. Beckmann, and W. Krelle, Fuzzy Multiple Attribute Decision Making: Methods and Applications, Springer, New York, NY, USA, 1992.

[18] F. Herrera and L. Martínez, "A 2-tuple fuzzy linguistic representation model for computing with words," IEEE Transactions on Fuzzy Systems, vol. 8, no. 6, pp. 746-752, 2000.

[19] D. J. Dubois, Fuzzy Sets and Systems: Theory and Applications, Academic Press, 1980.

[20] R. R. Yager, "On the retranslation process in Zadeh's paradigm of computing with words," IEEE Transactions on Systems, Man, and Cybernetics B: Cybernetics, vol. 34, no. 2, pp. 1184-1195, 2004.

[21] M. Delgado, J. L. Verdegay, and M. A. Vila, "On aggregation operations of linguistic labels," International Journal of Intelligent Systems, vol. 8, no. 3, pp. 351-370, 1993.

[22] Z. Xu, "A method based on linguistic aggregation operators for group decision making with linguistic preference relations," Information Sciences, vol. 166, no. 1-4, pp. 19-30, 2004.

[23] J. Wang and J. Hao, "A new version of 2-tuple fuzzy linguistic representation model for computing with words," IEEE Transactions on Fuzzy Systems, vol. 14, no. 3, pp. 435-445, 2006.

[24] R. M. Rodríguez and L. Martínez, "An analysis of symbolic linguistic computing models in decision making," International Journal of General Systems, vol. 42, no. 1, pp. 121-136, 2013.

[25] W. Wang, "Evaluating new product development performance by fuzzy linguistic computing," Expert Systems with Applications, vol. 36, no. 6, pp. 9759-9766, 2009.

[26] W. Tai and C. Chen, "A new evaluation model for intellectual capital based on computing with linguistic variable," Expert Systems with Applications, vol. 36, no. 2, pp. 3483-3488, 2009.

[27] M. Li, "The method for product design selection with incomplete linguistic weight information based on quality function deployment in a fuzzy environment," Mathematical Problems in Engineering, vol. 2013, Article ID 943218, 10 pages, 2013.

[28] J. M. Moreno, J. M. del Castillo, C. Porcel, and E. HerreraViedma, "A quality evaluation methodology for health-related websites based on a 2-tuple fuzzy linguistic approach," Soft Computing, vol. 14, no. 8, pp. 887-897, 2010.

[29] E. Herrera-Viedma, F. Herrera, L. Martínez, J. C. Herrera, and A. G. López, "Incorporating filtering techniques in a fuzzy linguistic multi-agent model for information gathering on the web," Fuzzy Sets and Systems, vol. 148, no. 1, pp. 61-83, 2004.

[30] L. Martínez and F. Herrera, "An overview on the 2-tuple linguistic model for computing with words in decision making: extensions, applications and challenges," Information Sciences, vol. 207, pp. 1-18, 2012.

[31] S. Choi, D. Kang, J. Lim, and K. Kim, "A fact-oriented ontological approach to SAO-based function modeling of patents for implementing Function-based Technology Database," Expert Systems with Applications, vol. 39, no. 10, pp. 9129-9140, 2012.

[32] C. He and H. T. Loh, "Pattern-oriented associative rule-based patent classification," Expert Systems with Applications, vol. 37, no. 3, pp. 2395-2404, 2010.

[33] T. Montecchi, D. Russo, and Y. Liu, "Searching in cooperative patent classification: comparison between keyword and concept-based search," Advanced Engineering Informatics, vol. 27, no. 3, pp. 335-345, 2013.

[34] L. A. Zadeh, "The concept of a linguistic variable and its application to approximate reasoning-I," Information Sciences, vol. 8, no. 3, pp. 199-249, 1975.

[35] E. Herrera-Viedma and E. Peis, "Evaluating the informative quality of documents in SGML format from judgements by means of fuzzy linguistic techniques based on computing with words," Information Processing and Management, vol. 39, no. 2, pp. 233-249, 2003.

[36] M. Badaracco and L. Martínez, "A fuzzy linguistic algorithm for adaptive test in Intelligent Tutoring System based on competences," Expert Systems with Applications, vol. 40, no. 8, pp. 3073-3086, 2013. 


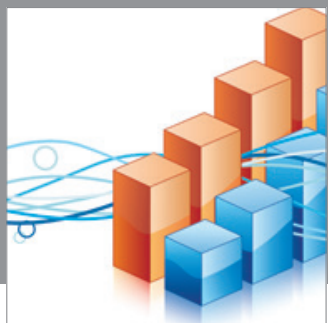

Advances in

Operations Research

mansans

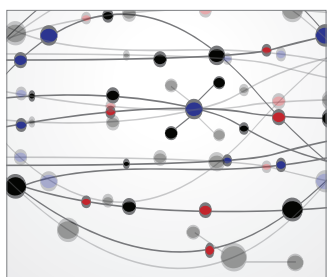

The Scientific World Journal
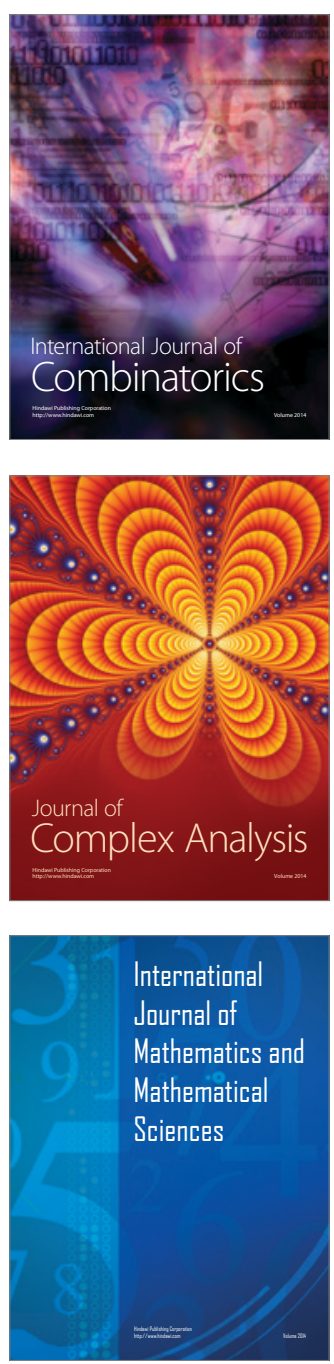
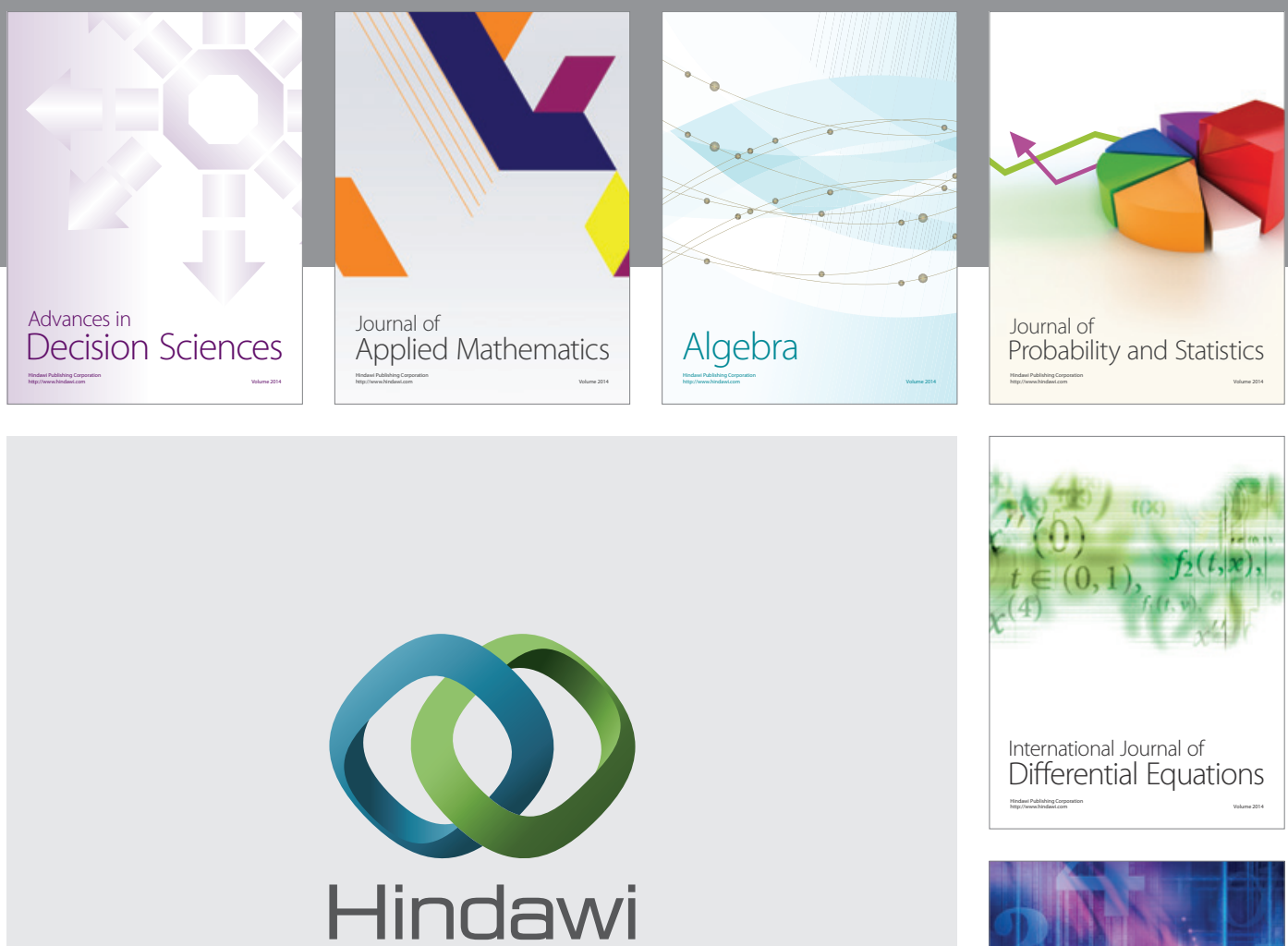

Submit your manuscripts at http://www.hindawi.com
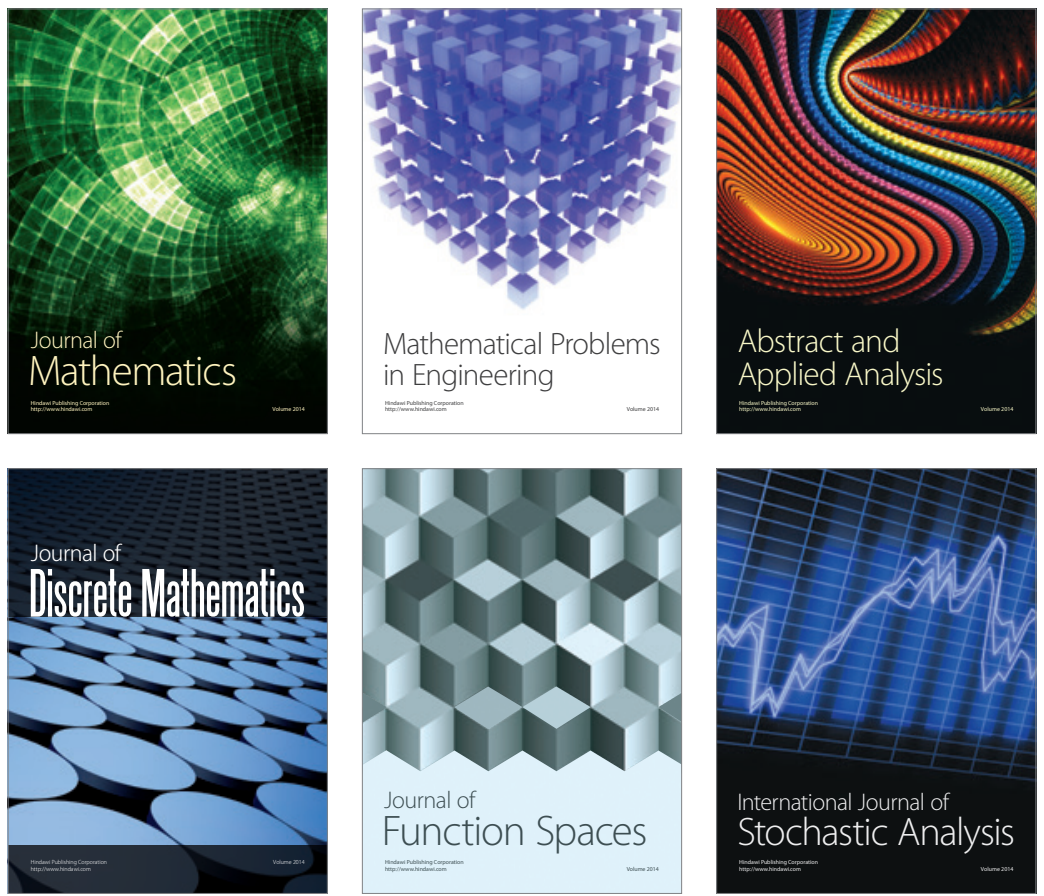

Journal of

Function Spaces

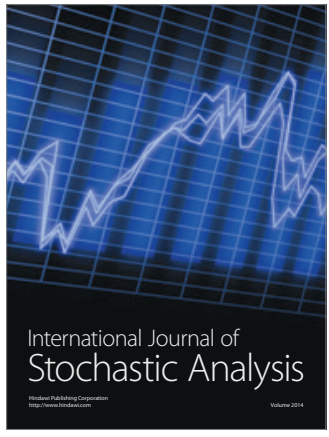

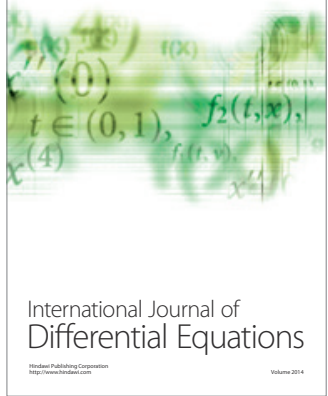
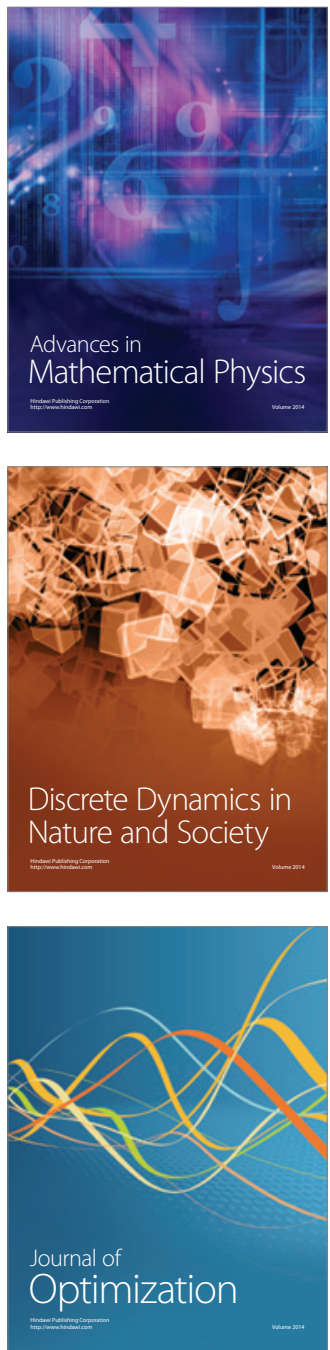